\title{
تطبيق أسلوب المناقثة الفئوية الصغرى و الندوة لترقية مهارة الكلام لطلبة قسم الأدب العربي بجامعة مالانج الحكومية
}

$$
\text { كرميلا أندرينا, إمام أسر اري, هنيء محلية الصحة }
$$

الملخص: يهدف هذا البحث إلى وصف إجراءات تطبيق أسلوب المناقثة الفئوية الصغرى والندوة

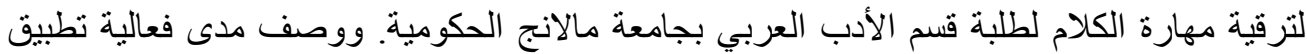

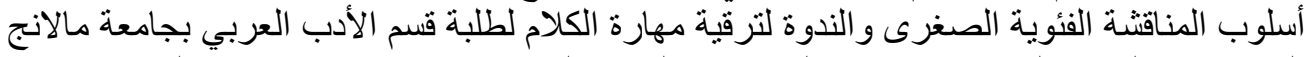

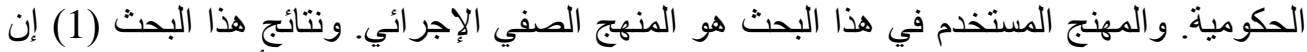

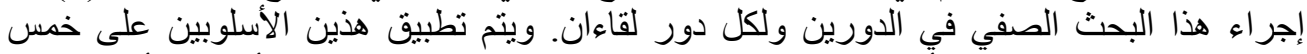

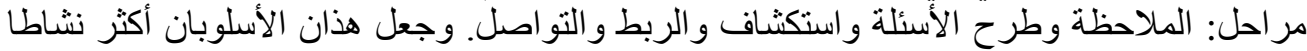

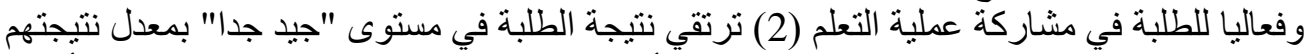

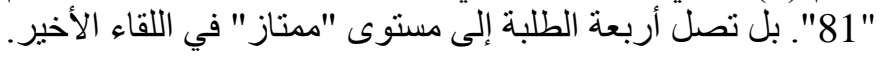

$$
\text { الكلمات الرئيسة: أسلوب المناقثة الفئوية الصغرى، الندوة، مهارة الكلام. }
$$

\begin{abstract}
Abstark: Penelitian ini bertujuan untuk mendeskripsikan (1) prosedur penerapan metode diskusi kelompok kecil dan seminar untuk meningkatkan keterampilan berbicara bagi mahasiswa Sastra Arab Universitas Negeri Malang, (2) dan tingkat evektifitas metode Diskusi kelompok kecil dan seminar untuk meningkatkan keterampilan berbicara bagi mahasiswa Sastra Arab Universitas Negeri Malang. Penelitian ini menggunakan metode penelitian tindakan kelas. Penelitian tindakan kelas ini dilaksanakan dalam dua siklus. Kegiatan inti dilakukan dalam 5 tahap, yaitu mengamati, mempertanyakan, mengeksplorasi, mengasosiasi dan mengkomunikasikan. Metode ini menjadikan mahasiswa lebih aktif dalam mengikuti proses pembelajaran. Semua mahasiswa lulus dalam pencapaian standar ketuntasan yang telah ditentukan dalam keterampilan berbicara. Nilai mahasiswa meningkat pada predikat "baik sekali" dengan rata-rata nilai "81". bahkan 4 mahasiswa memperoleh predikat "istimewa" di akhir pertemuan.
\end{abstract}

Kata Kund: Metode Diskusi Kelompok Kecil, Metode Seminar, Keterampilan Berbicara.

$$
\begin{aligned}
& \text { اللغة هي الوسيطة تستخدم لتبادل الأفكار والمشاعر بين أعضاء جماعة لغوية متجانسة. واللغة العربية لها } \\
& \text { أربع مهارات لغوية إحداها مهارة الكلام. ويعد الكالام مهارة ثانية من المهارات اللغوية التي يكتسبها الفرد } \\
& \text { في سنى حياته الأولى بعد مهارة الاستماع. مهارة الكلام القدرة على التعبير الشفوي عن المشاعر الإنسانية }
\end{aligned}
$$


والمواقف الاجتماعية والسياسية والاقتصادية والثقافية بطريقة وظيفية أو إبداعية مع سلامة النطق وحسن

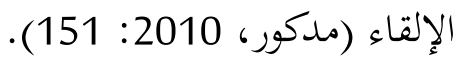

اهتم المدرسون ومحبو اللغة وكذلك وزارة التعليم والثقافة في إندونيسيا بموقف مهارة الكلام إذ هي

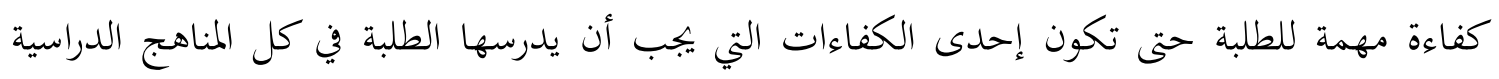
وخاصة في المنهج 2013. وذلك لأن الإنسان قد عرف الكلام قبل أن يعرف الكتابة بزمان طويل، ويتعلم

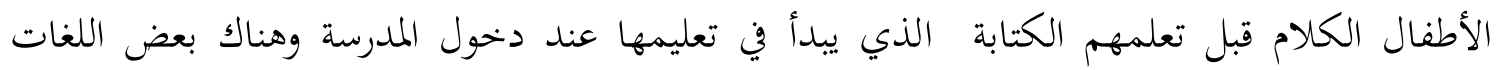

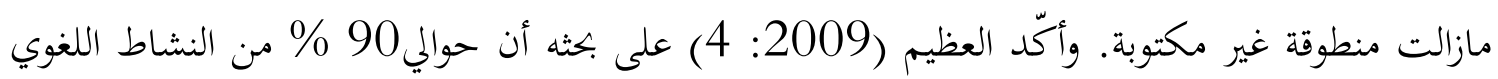
يكون شفهيا، والأنشطة الشفهية تعتبر مرجعا مهما أكثر من التعبير التحريري.

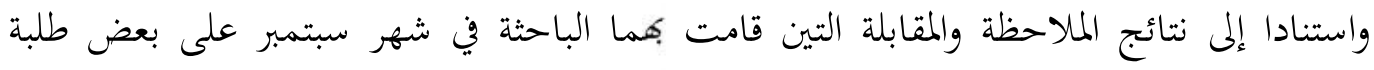

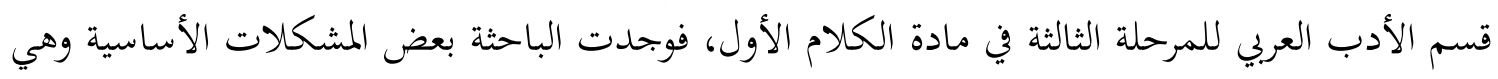

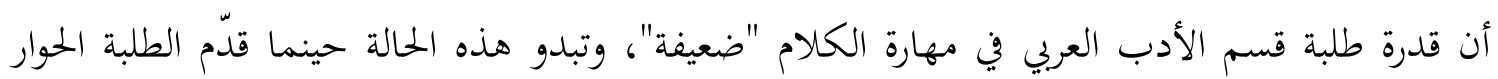
أمام الفصل، هؤلاء يشعرون بالتواتر والقلق والخجل وبعضهم الآخرون يحتاجون إلى مساعدة المدرس للتعبير

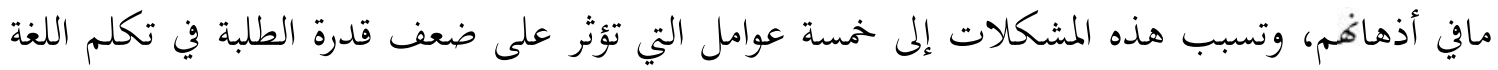

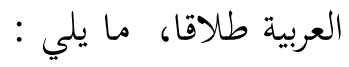
العامل الأول بيئة الفصل الدراسي. إنها لم تؤيد الأنشطة التحدثية لأن بعض المدرسين لايزالون

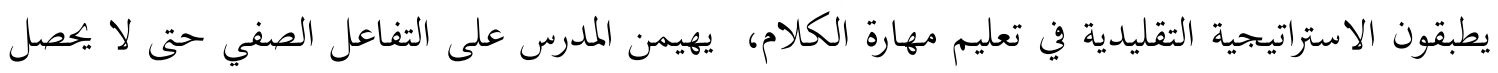

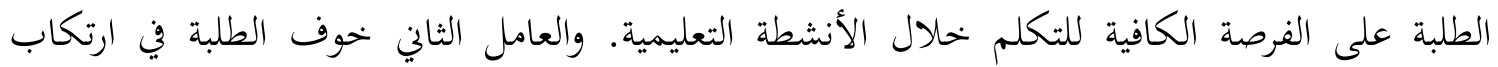

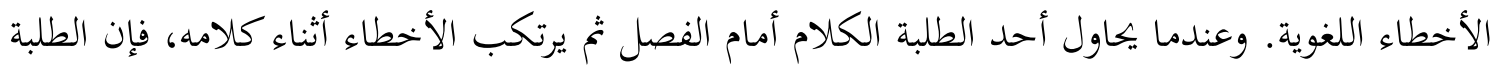
الآخرين يضحكون ويهملونه حتى يشعروا بالخجل. وعلاوة على ذلك، عندما يصحح المدرس تصحيحا

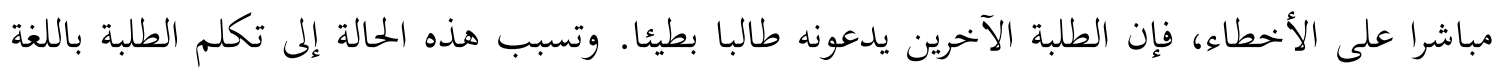
العربية غير طلاقة وسلاسة. والعامل الثالث قلة الدافعية في نفس الطلبة إما الدافع الداخلي أو الدافع الخارجي. تنعكس أنشطة

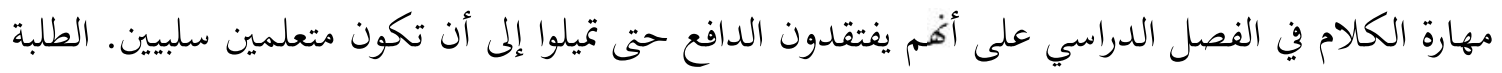

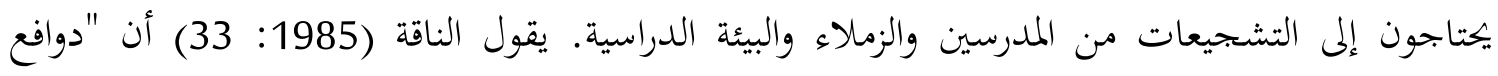
الدارسين تلعب دورا في غاية الأهمية في تعلم اللغة العبية من حيث أهدافها وبرابحها وطرقها ووسائل 


\section{8| BAHASA DAN SENI, Tahun 46, Nomor 1, Februari 2018}

أما العامل الرابع فعدم سيطرة الطلبة على المفردات الكثيرة حتى يجعلهم غير سلاسة وطلاقة للتكلم

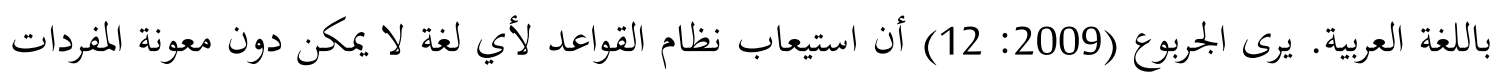

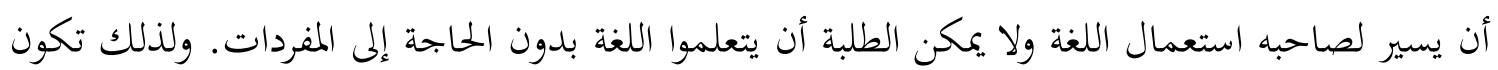
المفردات إحدى طرق النجاح في إتقان المهارات اللغوية.

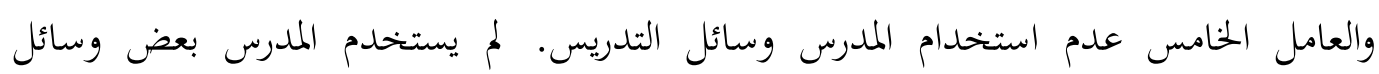

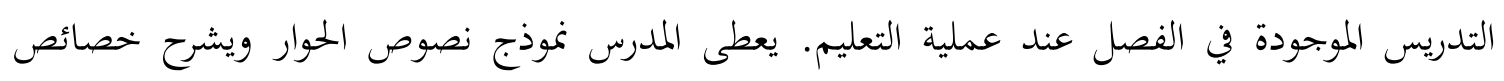

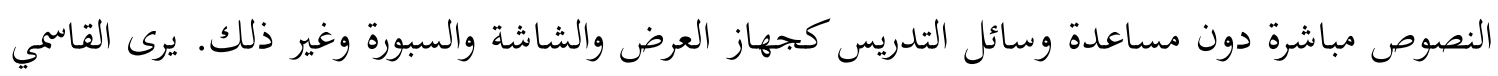
والسيد (1991: 5) أن وسائل التدريس كل مايثير شوق المتعلمين ويزيد من دافعيتهم للتعلم. فمن الأفضل أن يستخدم المدرس وسائل التدريس لمساعدة الطلبة على التكلم بالعربية بسهولة ويزيد تشجيعهم وفيها كذلك تنشأ تعلم مهارة الكلام البهيجة.

بالإضافة إلى ذلك، يجب على المدرسين أن يبتكروا تعليما مثاليا ليكون أحوال الطلبة فرحة وجذابة

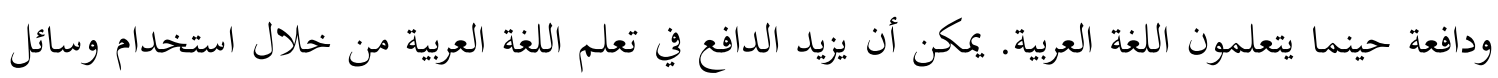

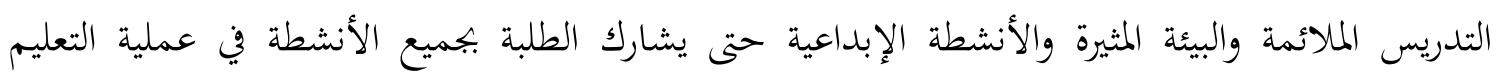

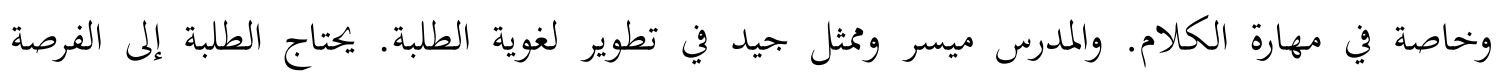

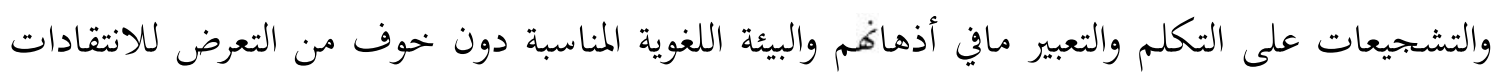
من قبل زملائهم وأصدقائهم.

هناك استراتيجيات عديدة يمكن أن يستخدمها المدرس في تدريس مهارة الكلام مثل الحوار واللعب

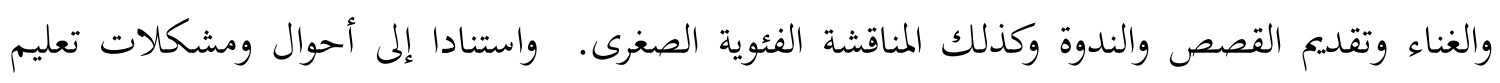

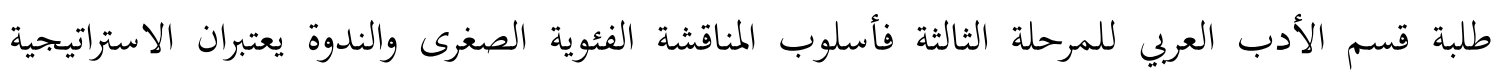
الأكثر فعالية في تدريس مهارة الكلام من خلال إعطاء المزيد من الوقت للتعبير عن أفكارهم وآراءهم وتقديم التعليقات والانتقدات في فئاتم الصغيرة.

اقتزح الناقة (1985: 28) على تخطيط عملية التعليم وتعلم اللغة الأجنبية وخاصة اللغة العربية من

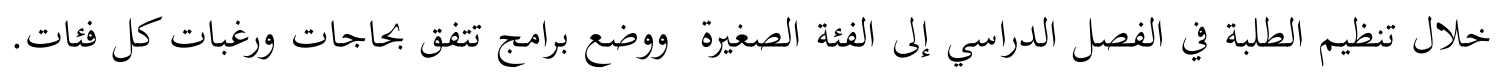

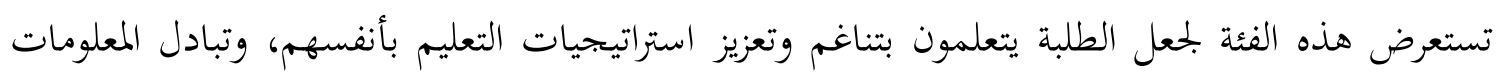

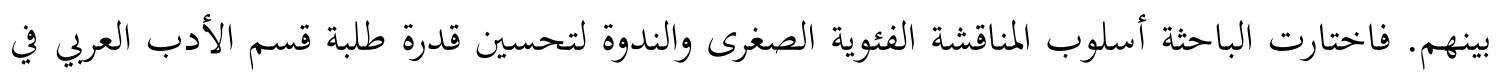

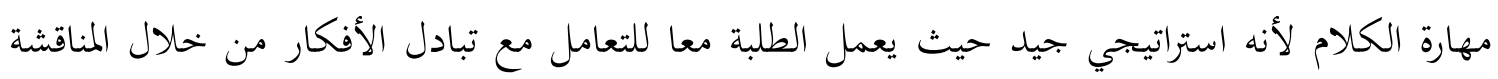

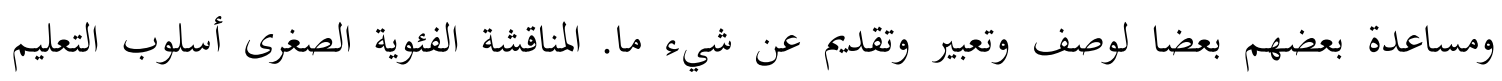


المستقل، ويتكون من أربعة إلى ستة أشخاص لجعل أنشطة التعليم أكثر متعة للطلبة، وكذلك لتدريب الطلبة في ضبط الوقت واستخدام المحموعة المتنوعة من المصادر. ومن خصائص أسلوب المناقشة الفئوية الصغرى مايلي : (1) وجود التعاون بين أعضاء البحموعة و(2) وجود تبادل المهارات في البحموعة (3) ووجود دور فعال لكل عضو في المشاركة (Hardiyansyah ، 2014: 2 . اتفق بما قاله الناقة، فقدّم ماجد (2013: 204) على امتياز أسلوب المناقشة عند تطبيقها في أنشطة التعليم، منها: أولا، يمكن أن يهفز الطلبة بأن يكونوا أكثر إبداعا، لاسيما في تقديم فكرغم ورأيهم. وثانيا، تدريبا لهم تعويدا على طرح الأفكار لحلول أي مشاكل. وثالثا، تدريبا لهم لتقدير على التعبير عن آرائهم أو أفكارهم لفظيا. بالإضافة إلى ذلك، يكون أسلوب المناقشة تدريبا للطلبة على احترام آراء الآخرين. وهكذا يؤكد سكيف (Skeff) وآخرون (1986: 320) على تنفيذ أسلوب الندوة في أنشطة التعليم، يقول سكيف وآخرون في مقالتهم بفعالية هذا الأسلوب الذي يأخذ ساعتين فحسب في كل دور، ويساعد أسلوب الندوة في تغيير سلوك المدرسين وزيادة تأثير المدرس على الطلبة وتعزيز مواقف الطلبة أكثر إيجابيا عند التدريس. وقد أجري بعض الدراسات السابقة لدعم أسلوب المناقشة الفئوية الصغرى والندوة في المهارت المختلفة وي المستويات العديدة، منها: دراسة اسماعيل (2014) التعرف علي أثر المناقشة الفئوية الصغرى لطلبة الصف الثاني في المدرسة الثانوية، استخدم هذا البحث المنهج الصفي الإجرائي الذي يقوم بالتعاون مع المعلمين الآخرين للغة الإبحليزية. في دور واحد بكوث الإجراءات، منها : التخطيط والتنفيذ والمراقبة والتفكير في طبقة العمل. وقد أجريت هذه الدراسة في الدور الواحد التي يتضمن على أربع لقاءات. وقد أسفرت الدراسة عن عدة نتائج أهمها أن استخدام استراتيجية المناقشة البحموعة الصغيرة ناجح في تحسين قدرة الطلبة في مهارة الكلام للصول الطلبة من كل فئة (منخفضة، متوسطة، والعالية) على معايير النجاح المقررة. كما تناولت دراسة وكيرن وآخرون (2014) الكشف عن المناقشة في طرق تدريس اللغة الإبحليزية بالندوة: تسلق السلام في المدرسة العليا. وأشارت نتائج هذه الدراسة إلى تكوين هذا الأسلوب أكثر وضوحا وفعاليا لتطبيقها في تدريس اللغة الإبحليزية. واستنادا إلى الخلفيات السابقة، فأكدت الباحثة على استخدام أسلوب المناقشة الفئوية الصغرى والندوة في تعليم مهارة الكلام، وهذان الأسلوبان يقدران على حل المشاكل التي يواجهها الطلبة في مهارة الكلام. 
ويهدف هذا البحث إلى وصف إجراءات تطبيق أسلوب المناقشة الفئوية الصغرى والندوة لترقية

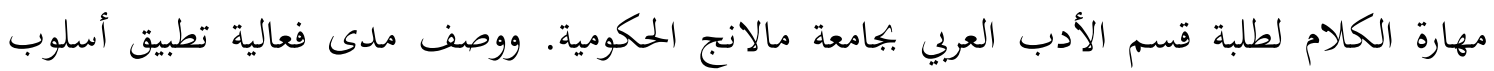
المناقشة الفئوية الصغرى والندوة لترقية مهارة الكلام لطلبة قسم الأدب العربي بحامعة مالانج الحكومية.

\section{منهيج البحث}

استخدمت الباحثة المنهج الصفي الإجرائي في هذا البحث. يتكون إجراء البحث من أربع

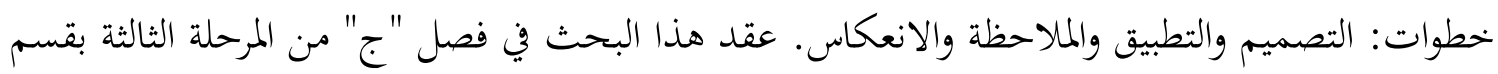
الأدب العربي بجامعة مالانج الحكومية. ركزت الباحثة بكثها في الفصل "ج" بقسم الأدب العربي للمرحلة

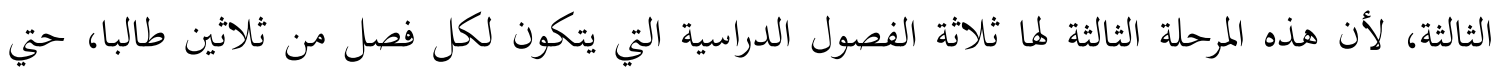

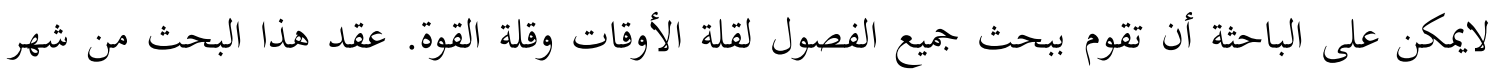
سبتمبر في السنة 2016 م.

البيانات الموجودة في هذا البحث هما البيانات الكيفية والبيانات الكمية. البيانات الكيفية في هذا البحث تعليم مهارة الكلام لطلبة فصل "ج" للمرحلة الثالثة بقسم الأدب العربي بجامعة مالانج الحكومية الذي يتكون من تعاون وأنشطة الطلبة في عملية التعليم وأنماط التفاعل بين الطلبة والمدرس وكذلك أنماط

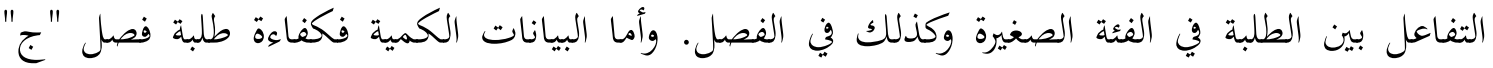
للمرحلة الثالثة بقسم الأدب العربي في مهارة الكلام.

وأدوات البحث المستخدمة في هذا البحث: (1) دليل الملاحظة، (2) دليل المقابلة، (3) أسئلة الاختبار، (4) ورقة الاستبانة. استخدمت الباحثة دليل الملاحظة لجممع البيانات عن الظواهر الموجودة

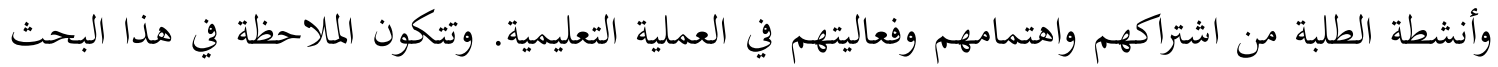
من قسمين: أولا، الملاحظة للباحثة بوصفها مدرسة، وثانيا الملاحظة للطلبة.

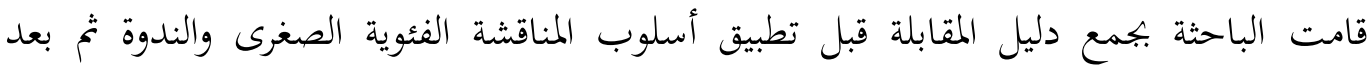
تطبيقهما للحصول على المعلومات المتعلقة بتنفيذ تدريس مهارة الكلام. وبعبارة أخرى لنيل الباحثة فئة الاقتراحات والتوصيات في ناية كل لقاءات لتحسين فعالية تنفيذ هذه الطريقة في الدور القادم، وكذلك

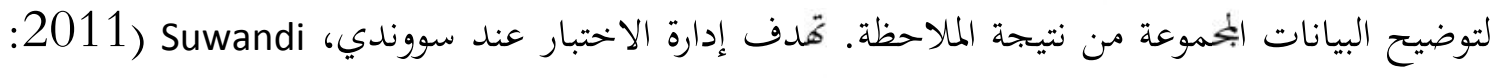
64) لقياس مدى نتائج الطلبة بعد التطبيق. قام الاختبار لتحديد مستوى ترقية كلام الطلبة وفقا بالدور الحالي. وقامت الباحثة بالاختبار القبلي والاختبار النصفي والاختبار الأخير. 
أعطت الباحثة ورقة الاستبانة للطلبة مرتين، قبل أنشطة البحث ثم في فاية البحث، لجمع البيانات المتعلقة برغبة الطلبة في قسم الأداب العربي يجامعة مالانج الحكومية للمرحلة الثالثة الذي يتعلق باهتمامهم وخبراهم في مهارة الكالام باللغة العربية، ولمعرفة تحسين جودة الطلبة في مهارة الكام وكذلك لمعرفة زيادة تشجيعهم فيها.

قامت الباحثة بعملية تحليل البيانات ببعض الخطوات مايلي: (1) جمع البيانات والتحقيق (إعادة

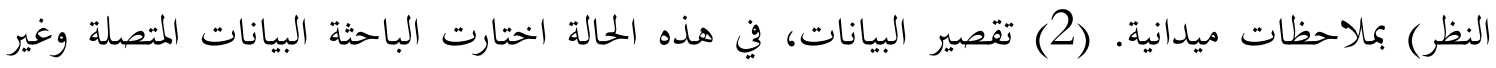

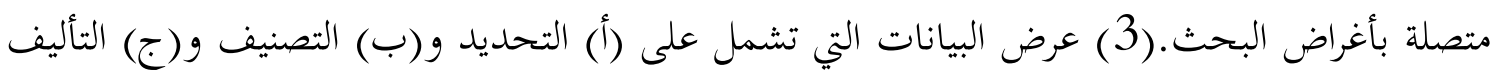

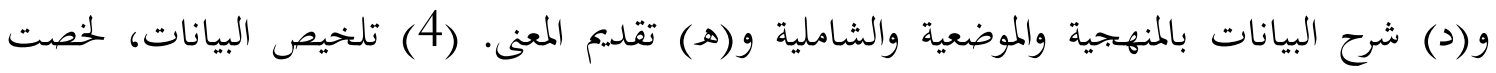
الباحثة نتائج البحث حسب تصنيف البحث.

احتاجت صحة النتائج للحصول على البيانات والاستنتاجات الصحيحة. للحصول على تصنيح تصحيح

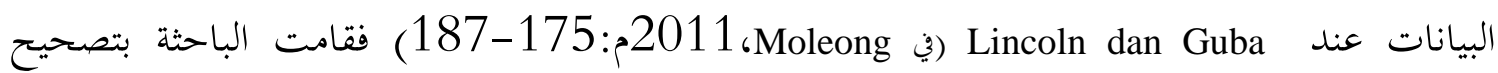
البيانات بالأنشطة الآتية: (1) الملاحظة المستمرة بعملية التدريس للحصول على البيانات الصحيحة. (2)

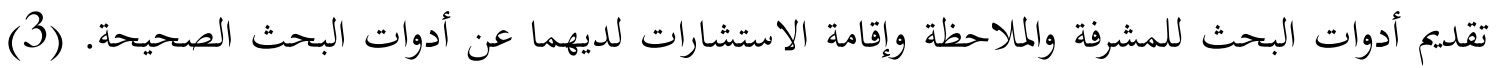
تفتيش البيانات ومصادرها.

لتحديد بناح تدريس مهارة الكلام بأسلوب المناقشة الفئوية الصغرى والندوة فلاحظت الباحثة

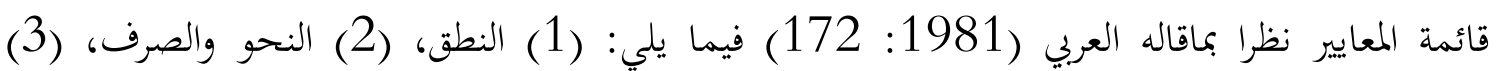
المفردات اللغوية، (4) الطلاقة، (5) الاستماع والفهم. فمن هنا نستطيع أن نحدد أن الاختبار في مهارة الكلام يعتمد على خمسة أشياء: القدرة على النطق الصحيح للأصوات اللغوية، ثم استخدام الكفاءة اللغوية من النحو والصرف والمفردات اللغوية، ثم الطلاقة والسلاسة في اختيار التراكيب اللغوية، وقدرة المتكلم على الاستماع والفهم.

\section{نتائج البحث والمناقشة} إجراءات تطبيق أسلوب المناقشة الفئوية الصغرى والندوة لترقية مهارة الكلام

وضح تطبيق أسلوب المناقشة الفئوية الصغرى والندوة في خطوات التدريس من الدور الأول والدور الثاني، ولكل دور لقاءان. نفذت الباحثة في كل لقاءات بتطبيق أسلوب المناقشة الفئوية الصغرى والندوة

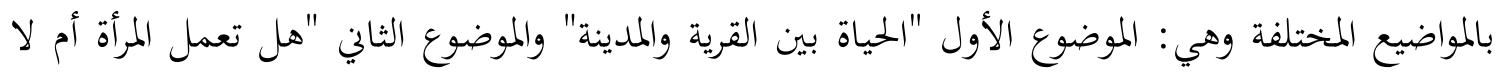


تعمل" والموضوع الثالث "وسائل الاتصال القديمة والحديثة" والموضوع الرابع "التعليم بين الماضي والحاضر".

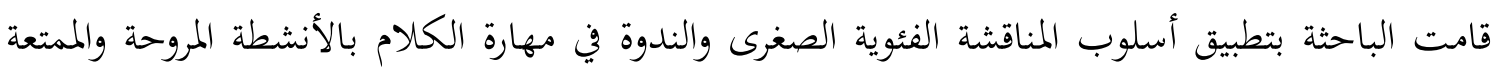

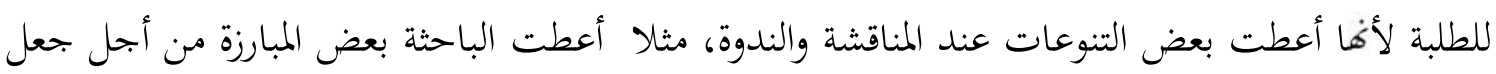

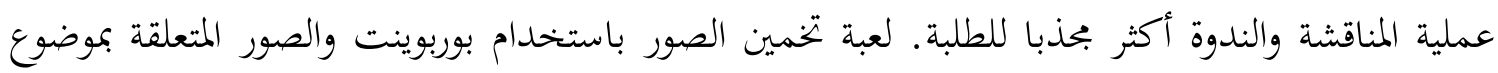

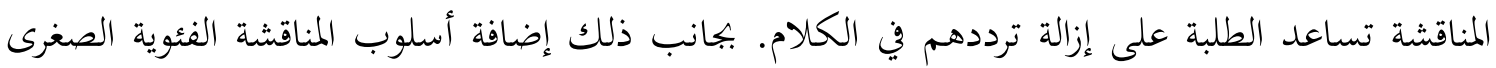
والندوة بمساعدة الصور يمكنان أن يزيدا أنشطة الطلبة ونتائج تعلمهم في مهارة الكلام (ساري (Sari)

بين حنبيلي (2007: 83) عن فوائد استخذام اللعب في التعليم، أن اللعب في التعليم يحل محلا

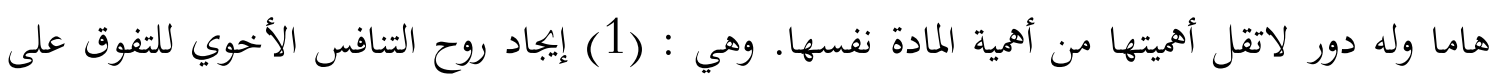
الآخرين، (2) حث النفس على تحسين إمكانتهم الذاتية، (3) التعاون مع الأقران أو الأصدقاء لانجاز

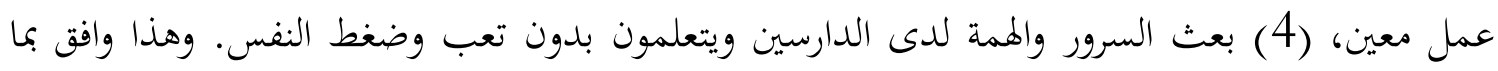

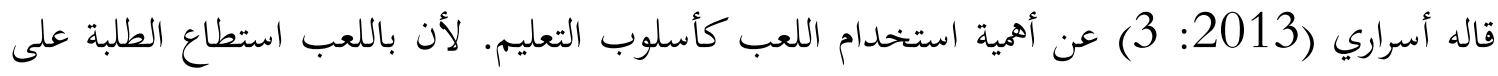
تحليل الموضوعات بسعادة دون إجبار .كما أن هذين الأسلوبين يشجعان الطلبة على تعلم اللغة العربية بوصف الصورة لاتصال بمجموعتهم الصغيرة. فإن هذين الأسلوبين يسببان الطلبة إلى تعلم المروح والممتع.

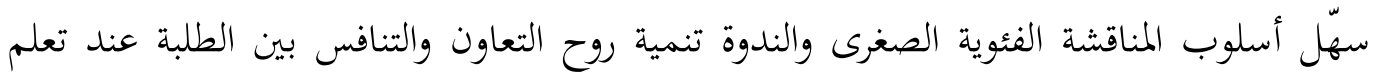
مهارة الكلام وتلك الحالة أتاحت الطلبة الفرصة الوفيرة ليمارسوا مهارات التفكير والاستماع والاتصال الشفهي وهم ينمون الجرأة الأدبية والشجاعة على إبداء الرأي ويذكرون المعلومات الدقيقة ويحترمون آراء

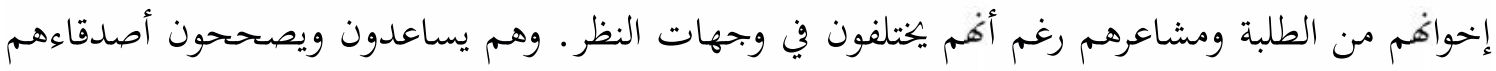

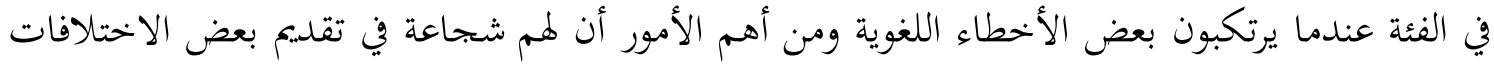

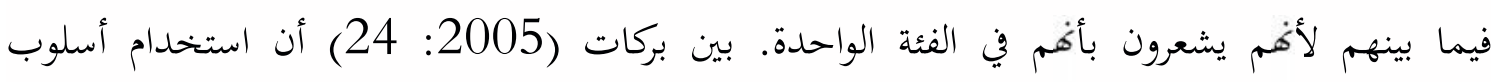
التدريس في الفئة الصغرى يسهم في رفع مستوى التحصيل بشكل عام. الطلبة داخل هذه الفئة يتعاونون في

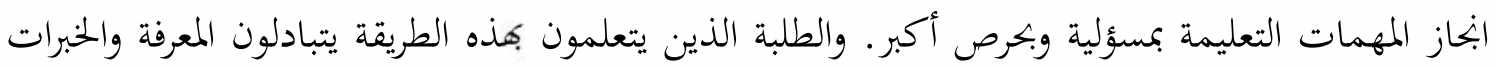
والأفكار فيما بينهم داخل البحموعة الواحدة، فهم لايشعرون بالمنافسة الفردية داخل البحموعة الواحدة وإنما تدفع الطلبة للعمل بجد وبفعالة منافسة البحموعات الآخرى. وعلاوة على ذلك، تعليم مهارة الكلام بتطبيق هذين الأسلوبين يجعل الطلبة قادرين على معرفة بعضهم البعض دون الخجل والخوف لأغم يتشاورون ويتكلمون مع أصدقائهم المعروفة. بهذين الأسلوبين

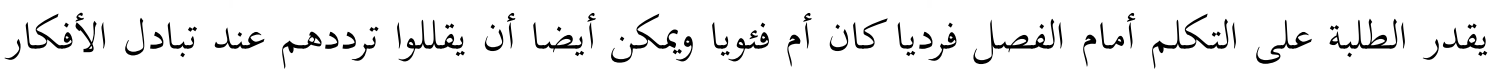


رغم أن هذين الأسلبين يحتجان إلى وقت وحصة كثيرة للحصول على التفاق التام على الشكل النهائي

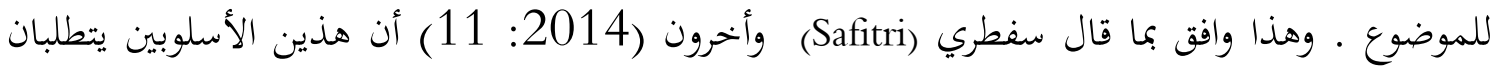
كثيرا من الوقت في تطبيقهما نتيجة من أحوال الطلبة المختلفة عند مشاركة أنشطة التعليم. وأما الطراونة (2012: 451) فيؤكد أن هذا الأسلوب له فوائد سلوكية فقد زاد من إيهابية النظرة الأكاديمية لدى الدى

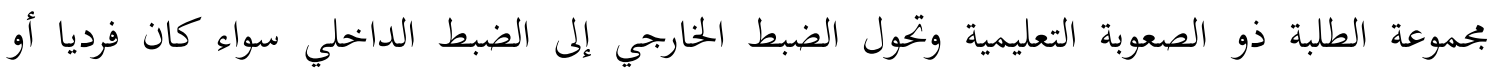
بحموعا. وهذا الأسلوب يدرب الطلبة على العمل ضمن فريق وإقامة علاقات إيبابية فيما بينهم مما يهعل عملية التعلم عملية اجتماعية تشجع على التعاون وتبادل المعلومات.

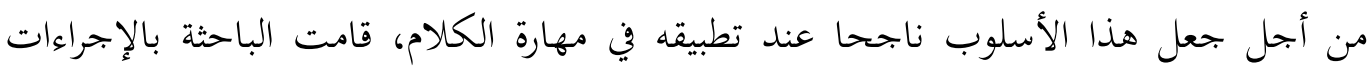
التالية (1) إعطاء بعض الصور لمساعدة الطلبة على عرض أفكارهم طبقا بالموضوع. (2) تكوين الأسئلة الرئيسية لثثير الطلبة على تذكير خصائص الصور المعروضة. (3) تقسيم الطلبة إلى الفئات الصغرى التي لتصني

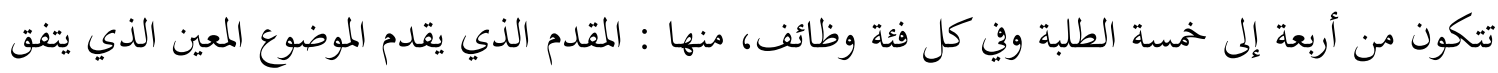

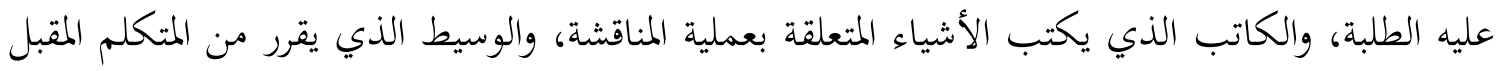

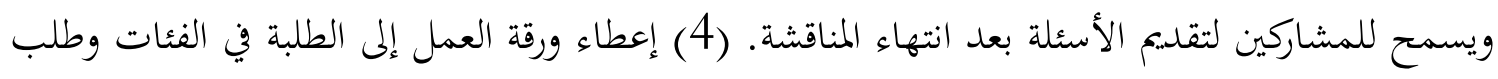
منهم لوصف خصائص الصور في ورقة العمل. (5) إجراء المناقشة التمهيدية في الفئة الصغيرة. (6) تقديم ولئه

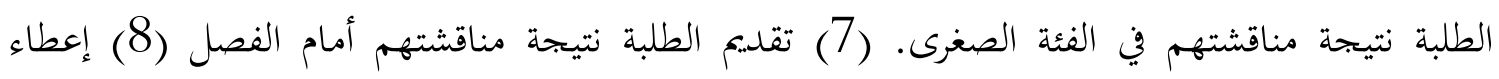

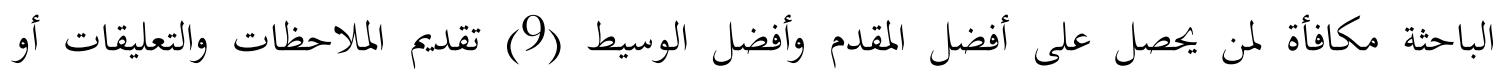
الانعكاس حول الأنشطة التعلمية والتعليمية في آخر اللقاء. وأخيرا، بعد قيام الباحثة بتلك العملية فاستبطت الباحثة أن كفاءة الطلبة في الكلام الأول بعد البعر تطبيق أسلوب المناقشة الفئوية الصغرى والندوة ترتقي وتعطي تأثيرا إيجابيا نحو تتزايد كفاءة الطلبة في الكلام

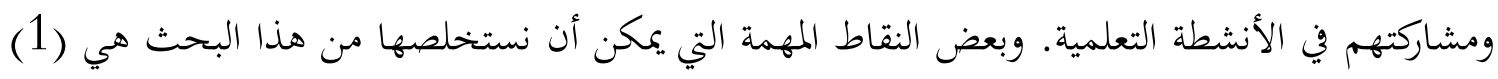

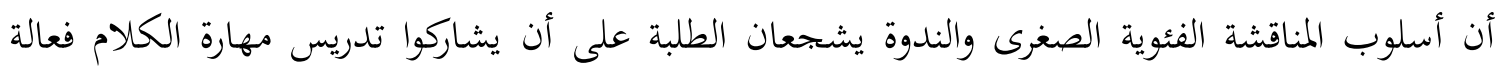

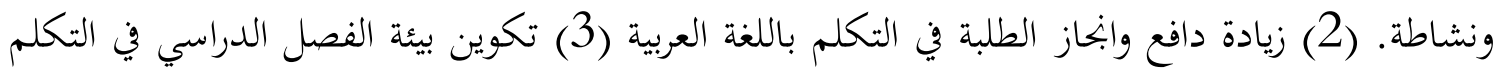
باللغة العربية مثيرة ومتتعة.

\section{مدى فعالية تطبيق أسلوب المناقشة الفئوية الصغرى والندوة لترقية مهارة الكلام}

كانت كفاءة الطلبة في مهارة الكلام في الاختبار القبلي، قبل تطبيق أسلوب المناقشة الفئوية الصغرى

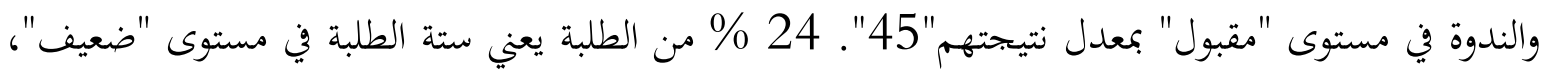


و56 \% من الطلبة يعني 14 طالبا في مستوى "مقبول"، و20 \% من الطلبة يعني خمسة الطلبة في مستوى

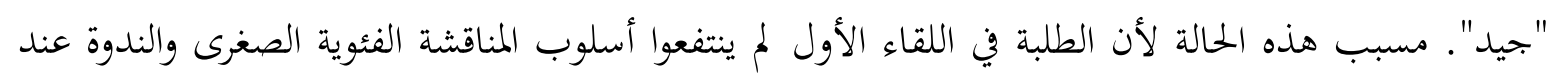

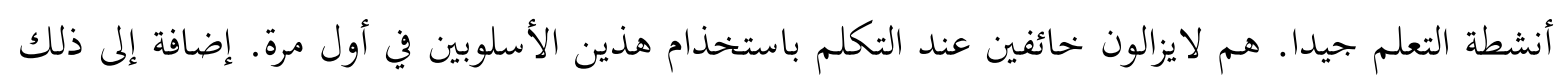
لم يسيطر الطلبة المفردات الكثيرة حتى يجعلهم غير سلاسة وطلاقة للتكلم باللغة العربية، وبين الناقة (1985:

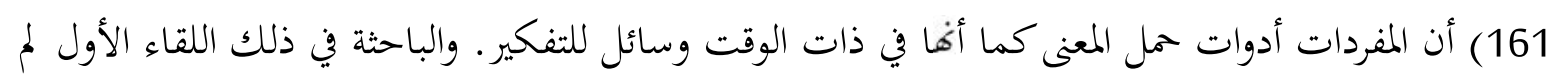

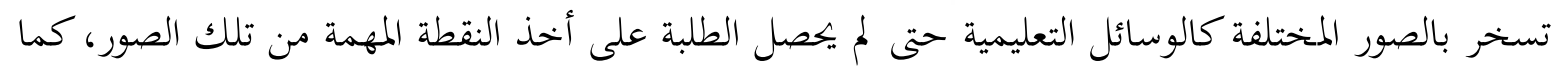

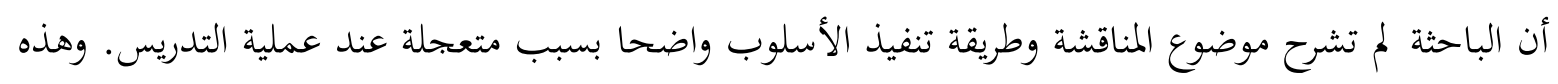

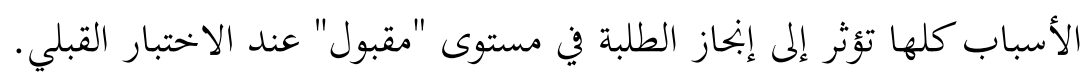

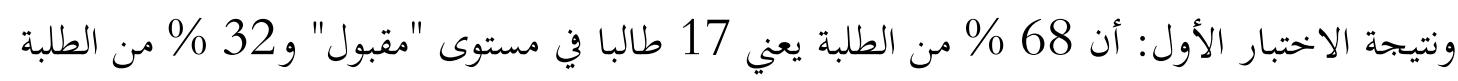

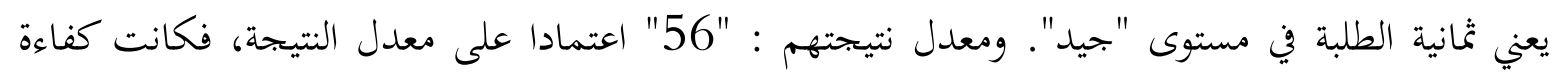

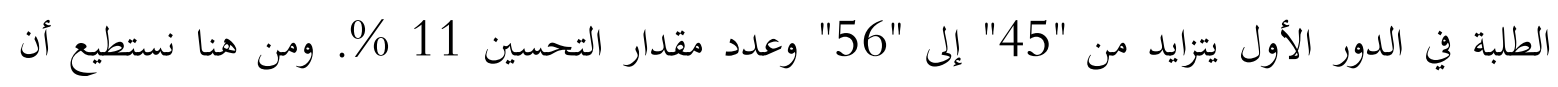

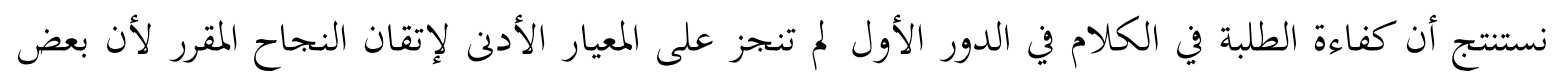

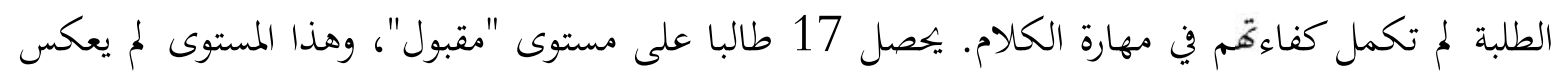

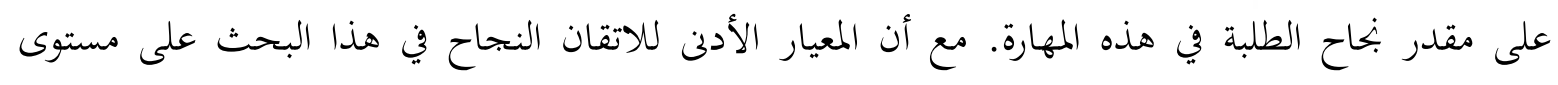

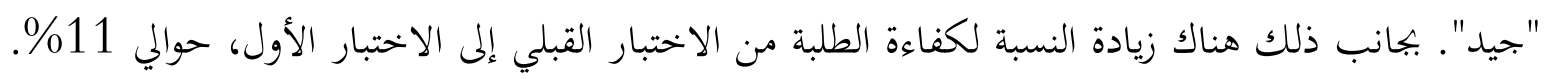

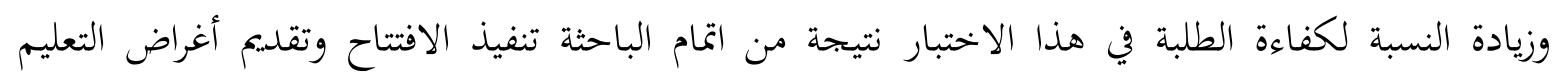

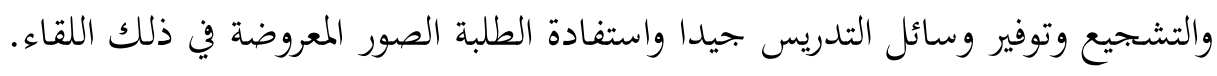

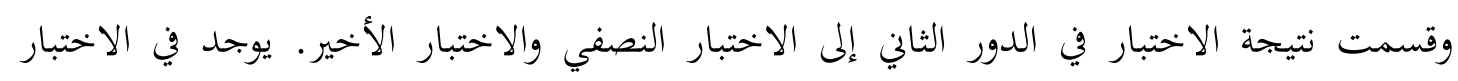

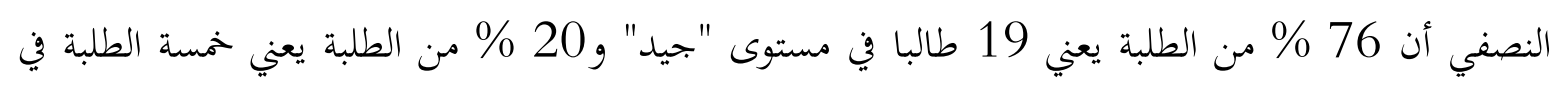
مستوى "جيد جدا" و4 \% من الطلبة وهي طالبة واحدة في مستوى "متاز". ولم يصل أحد منهم إلى مستوى

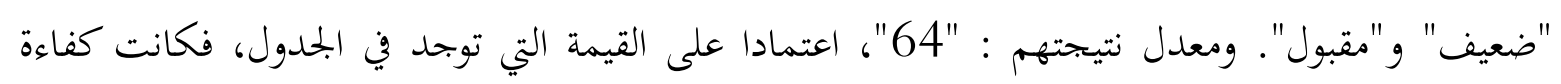

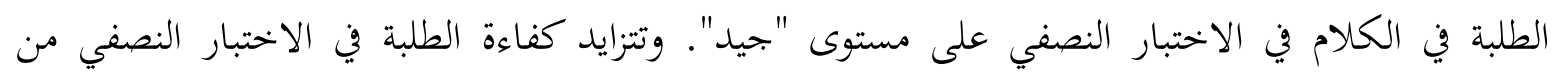

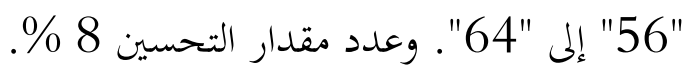

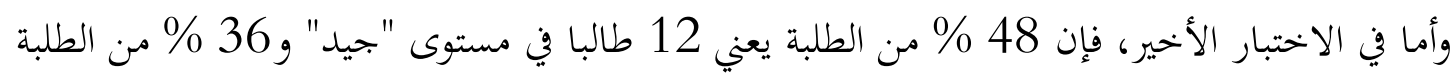

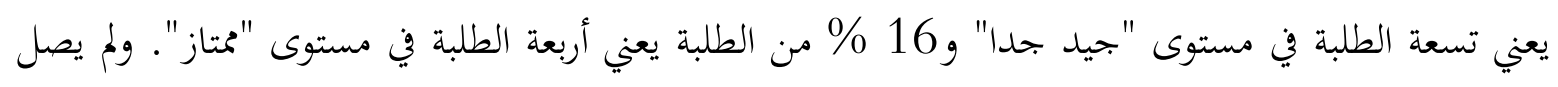

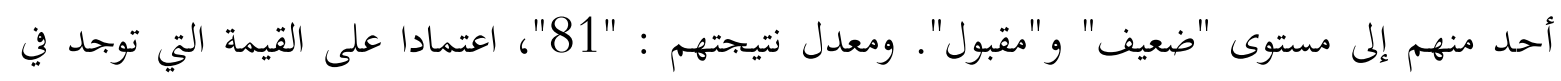

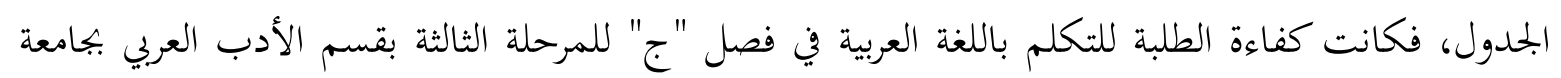


مالانج الحكومية بعد القيام بتطبيق أسلوب المناقشة الفئوية الصغرى والندوة في الاختبار الأخير على مستوى "جيد جدا". وتتزايد كفاءة الطلبة في الاختبار الأخير من "64" إلى "81". وعدد مقدار التحسين 17 \%٪.

الجدول 1 : نسبة تحسين كفاءة الطلبة في الكلام

\begin{tabular}{|c|c|c|c|c|}
\hline مقدار التحسين & معيار النجاح & معدل النتائج & 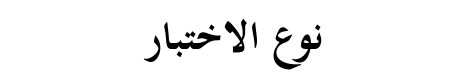 & 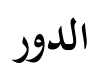 \\
\hline- & مقبول & 45 & الاختبار القبلي (اللقاء الأول) & 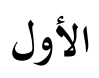 \\
\hline$\% 11$ & مقبول & 56 & الاختبار الأول (اللقاء الثاني) & \\
\hline$\% 8$ & جيد & 64 & الاختبار النصفي (اللقاء الثالث) & 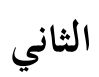 \\
\hline$\% 17$ & جيد جدا & 81 & الاختبار الأخير (اللقاء الرابع) & \\
\hline
\end{tabular}

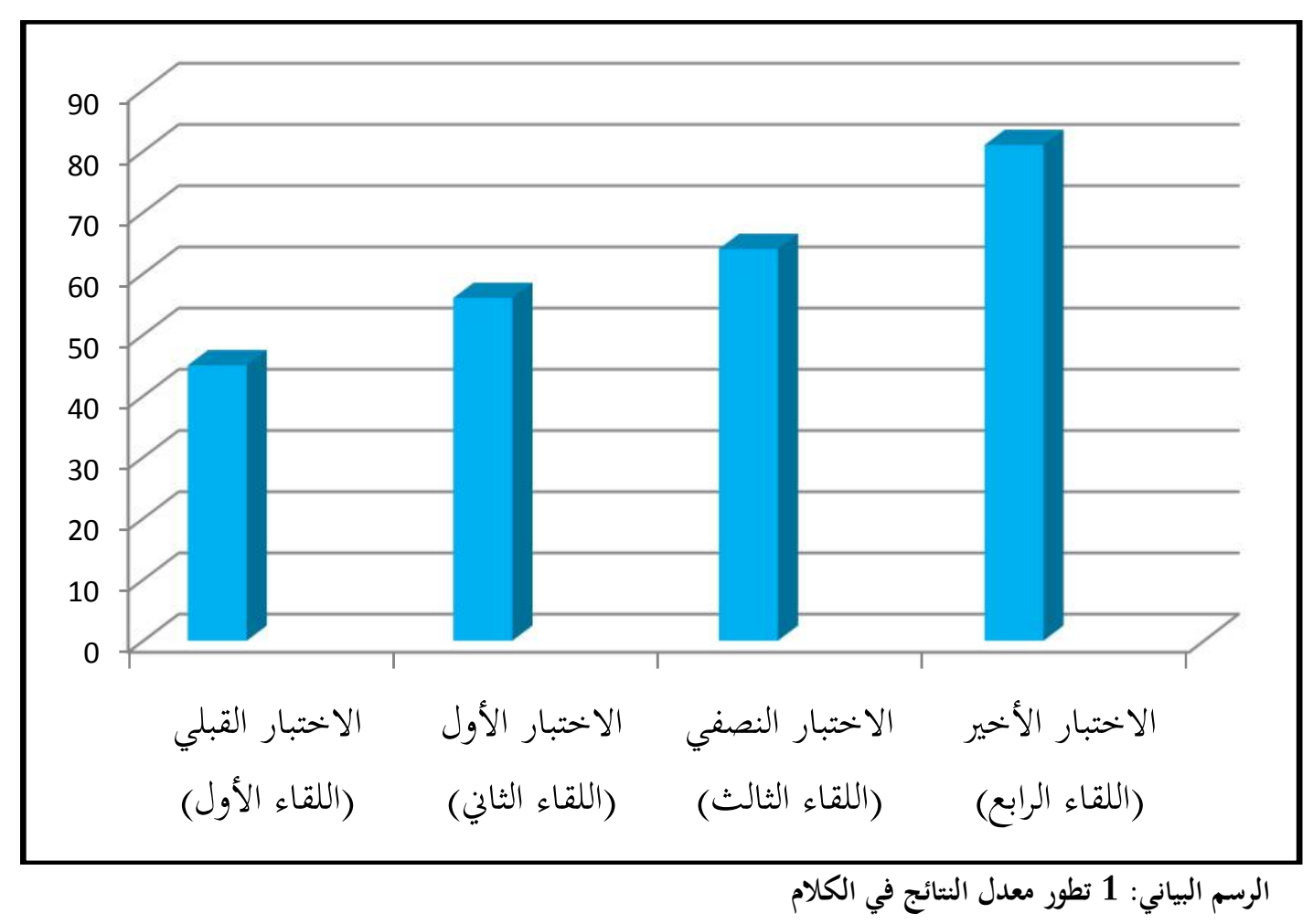


من هنا تستنتج الباحثة أن جميع الطلبة في هذا الدور الثاني "ناجحون" لتكميل ولإنخاز معيار النجاح

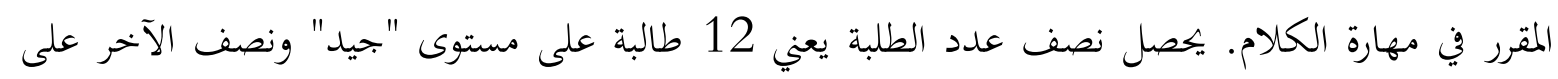

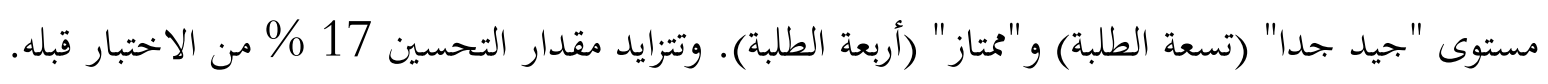

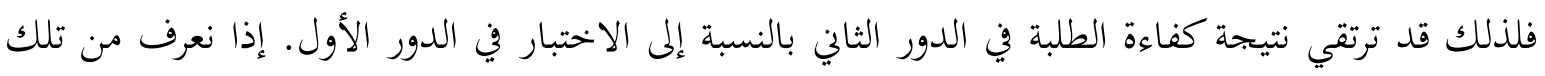

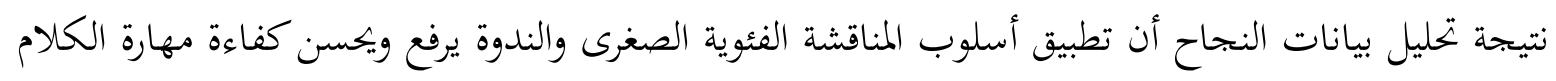
للمرحلة الثالثة بقسم الأدب العربي بجامعة مالانج الحكومية. حدثت تغييرات الطلبة نتيجة من الأنشطة التعليمية في الفصل الدراسي مظهر على كفاءوبة الداءة الطلبة المرتقية

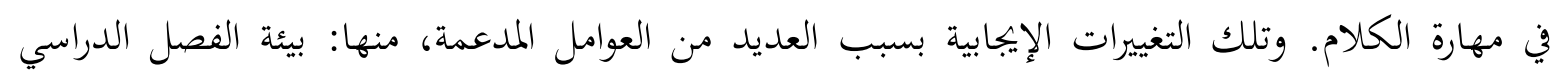

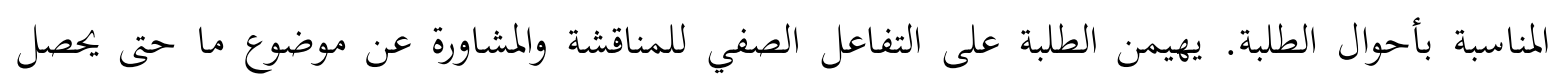
الطلبة على الفرصة الكافية للتكلم خلال الأنشطة التعليمية بتطبيق أسلوب المناقشة الفئوية الصغرى والندوة.

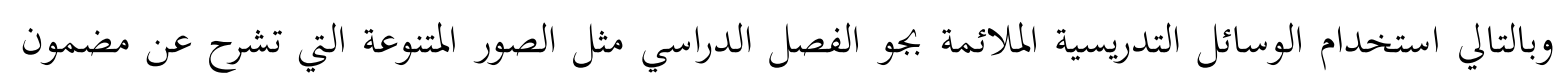
موضوع المناقشة والندوة المتعمدة. تم إعطاء التشجيعات والدوافع الوافرة للطلبة كي لا يخافوا في ارتكاب الأخطاء اللغوية أثناء كلامهم أو أو أنساء

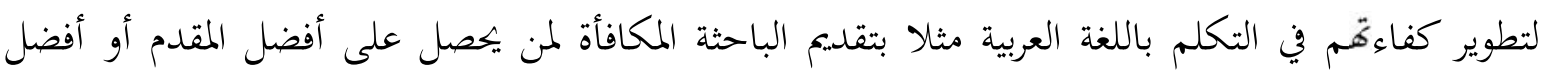
الوسيط عند المناقشة والندوة. وكذلك إعطاء التشجيع والتعزيز للطلبة يقدران على رفع ثقتهم، حتى لا لا يتردد

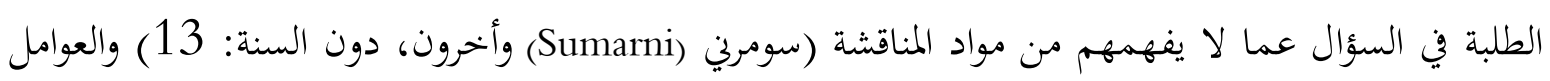
الأخيرة تطبيق الباحثة أسلوب التعليم الموافقة بمشكلات تعليم الطلبة من خلال إعطاء إنماء المزيد من الوقت للتعبير عن أفكارهم وآراءهم وتقديم التعليقات فرديا كان أم فئويا حتى تتحقق أغراض تعليم مهارة الكلام المصممة.

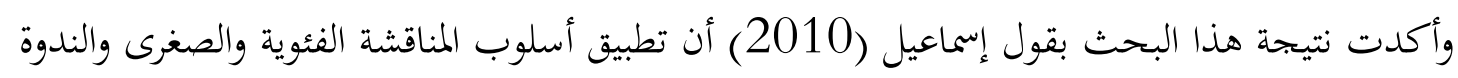

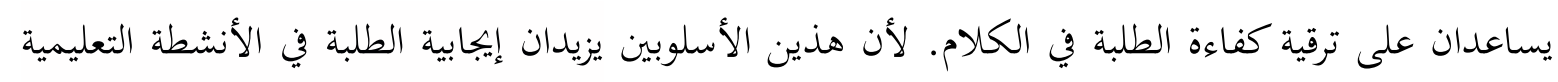

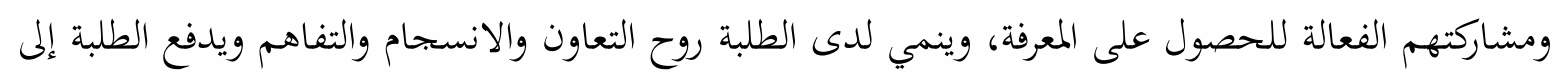

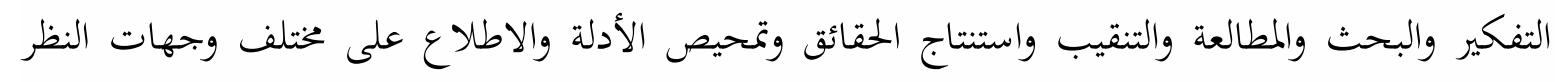

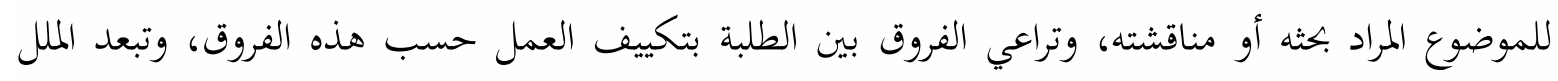

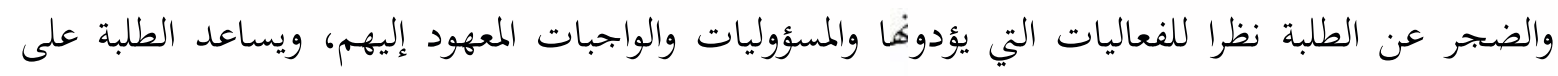
عدم نسيان المعلومات العلمية التي أعدوها بأنفسهم واتبعوا في تحضيرها وتقديمها للمناقشة.

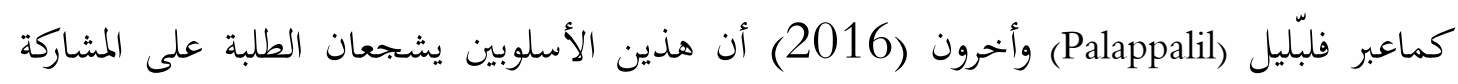
الفعالة في عملية المناقشة والندوات ويساعدن على تمنية الحماس والاهتمام لتعلم وتحسين مهارة التواصل، 
والتفاعل بين الزملاء والعمل الجماعي وتنظيم عرض تقديمي. وهذان الأسلوبان سوف يساعدان الطلبة على

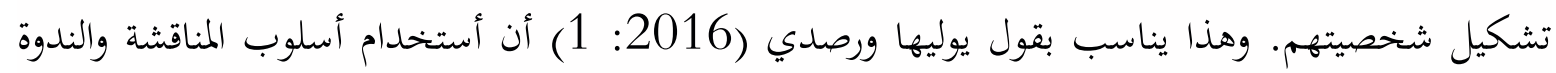
يقدران على زيادة نتائج الطالبة في التعلم.

الاختتام

الخلاصية

إن استخدام أسلوب المناقشة الفئوية الصغرى والندوة يقدران على تحسين كفاءة الطلبة في الكلام لفصل

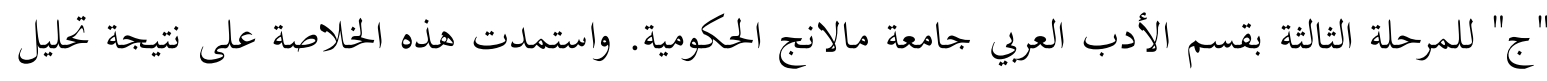

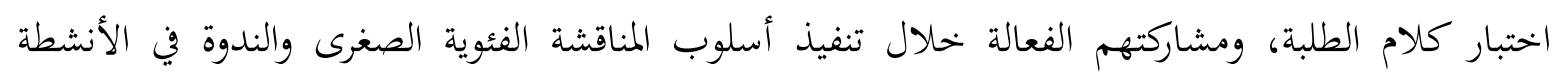

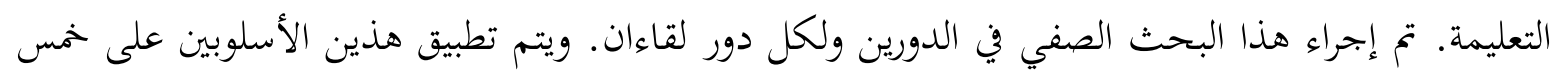

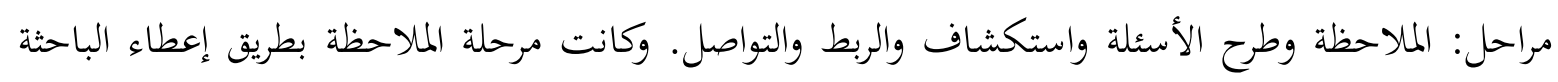

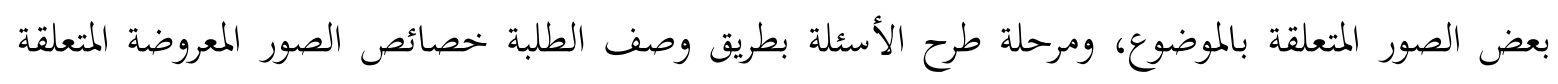

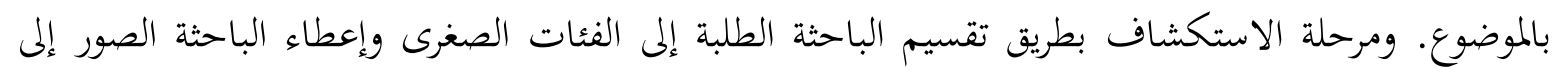

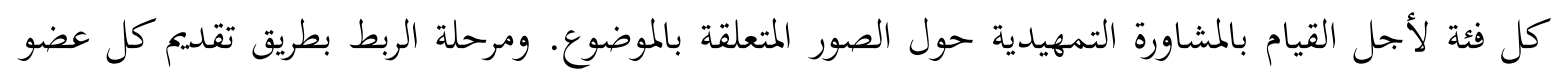

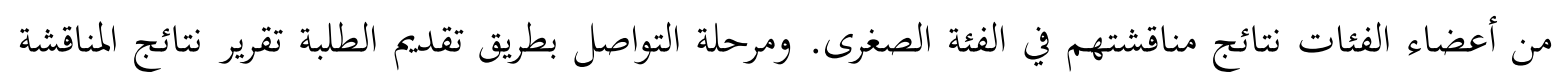

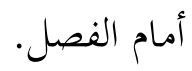
إشارة إلى نتائج اختبار الكلام في أخر اللقاء، وجدت الباحثة أن جميع الطلبة ينجزون المعيار الأدنى

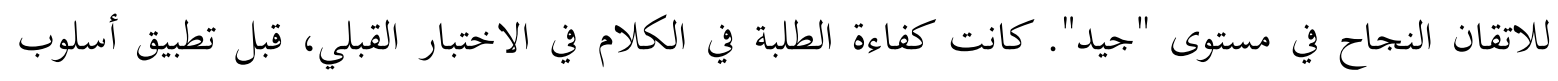

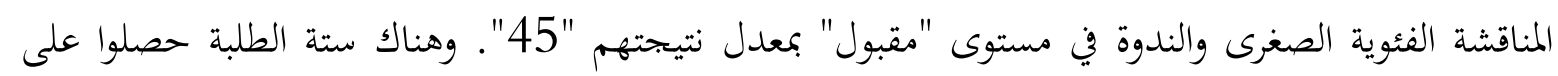
مستوى "ضعيف" في هذا اللقاء الأول. ولكن بعد تطبيق الباحثة أسلوب المناقشة الفئوية الصغرى والندوة

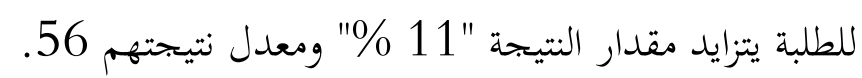

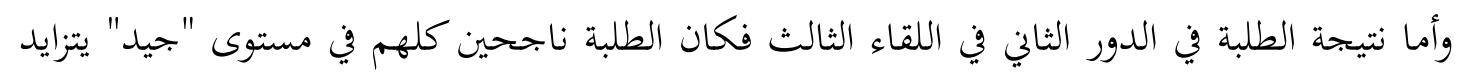

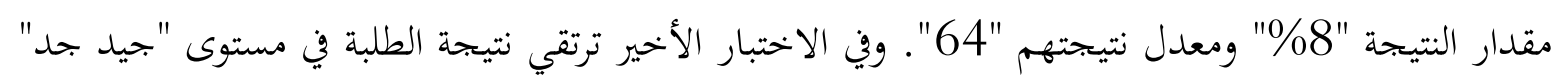

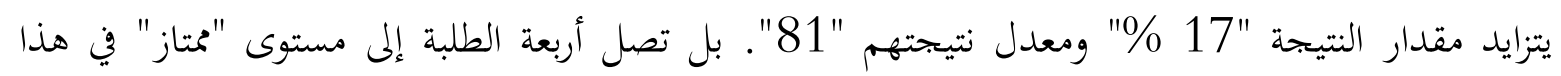
اللقاء الآخير.

وهذا بمعنى أن تنفيذ وتطبيق أسلوب المناقشة الفئوية الصغرى والندوة في تدريس الكلام يقدران على الكي تخفيض بعض مشكلات الطلبة في الكلام ومنها: خوفهم في التكلم اللغة العربية مثل القلق أو التردد في الكلام 
ولديهم المفردات المحدودة للتعبير عن أفكارهم والفرصة الضئيلة لاتصال مع الآخرين. والخلاصة، يعبر هذا

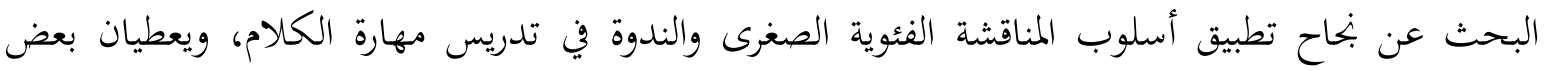
المنافع للطلبة في تدريس مهارة الكلام منها: تحسين كفاءة الطلبة وتتزايد مشاركة الطلبة في الأنشطة التعليمية لكتكلم باللغة العربية فعاليا ونشاطا.

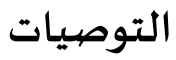

اعتمادا على نتائج هذا البحث الإجرائي "تطبيق أسلوب المناقشة الفئوية الصغرى والندوة لترقية مهارة

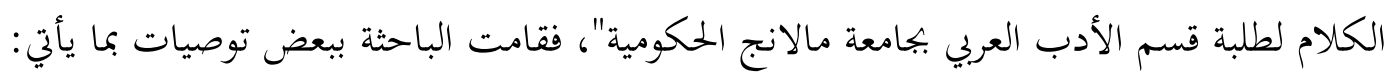

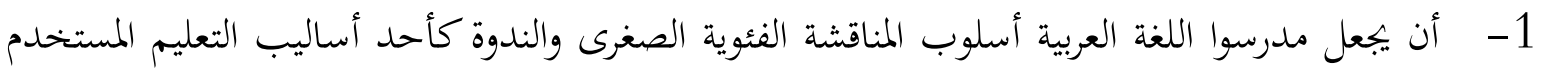
في الأنشطة التعليمية لكون هذين الأسلوبين أسلوبا فعاليا ومناسبا بأحوال الطلبة.

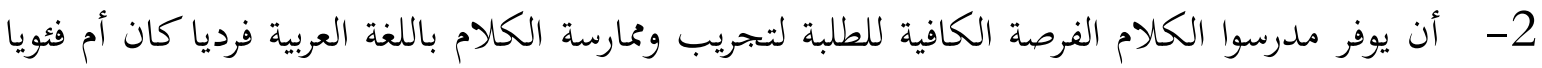

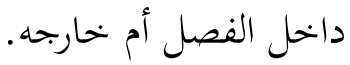

3- أن يعطي كل مدرس التشجيعات العالية للطلبة وأن يستخدموا وسائل التدريس مثل الصور وبوربوينت

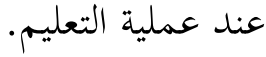
4- أن يجعل قسم تعليم اللغة العربية بجامعة مالانج الحكومية بيئة عربية لتكلم اللغة العربية لكون هذه البيئة عنصر مهم في نجاح عملية التدريس.

الجربوع، عبد الله سليمان. 2009. قائمة مكة للمغردات الشائعة. . جامعة أم القرى: مكة المكرمة.

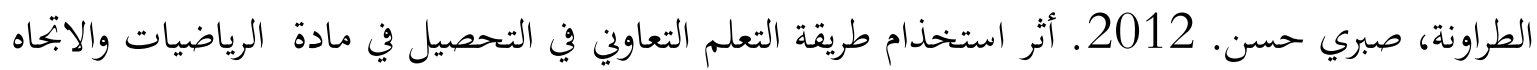
نحوها لطلبات الصف الثامن الأساسي. مجلة جامعة دمشق - البحلد 28-العلد الثالث: الأردن. العظيم، عبد. 2009. استخدام المناقشة في تنمية مهارة الكالام بالتطبيق على قسم اللغة العربية بجامعة مالانج الحكومية . جامعة مولانا مالك إبراهيم الاسلامية الحكومية: مالانج. القاسمي، علي والسيد، محمد علي. 1991. التقنيات التربوية في تدريس اللغة العربية لغير الناطقين بها.

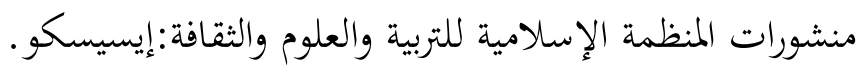




$$
\begin{aligned}
& 109 \text { | تطبيق أسلوب المناقثة الفئوية الصغرى, Indaryana, Asrori, Mahliatussikah } \\
& \text { الناقة، محمود كامل. 1985. برامج تعليم العربية للمسلمين الناطقين بلغات أخرى في ضوء دوافتهم (دراسة } \\
& \text { ميدنية) جامعة أم القرى:مكة المكرمة. } \\
& \text { بركات، زياد. 2005. أثر استخدام طريقة التعليم في مجمعوعات صغيرة على التحصيل الفوري والمؤجل لدى } \\
& \text { طالبات الصف الثاني الأساسي. جامعة القدس المفتوحة: فلسطين. }
\end{aligned}
$$

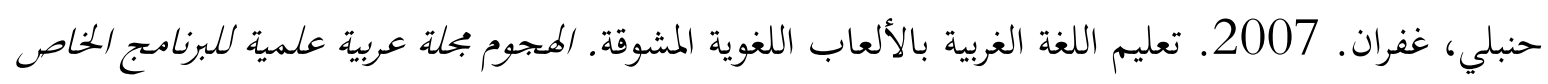

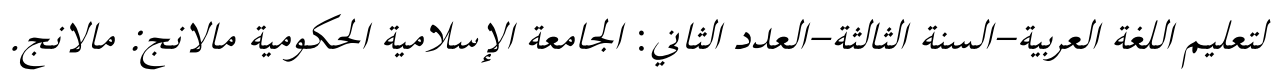

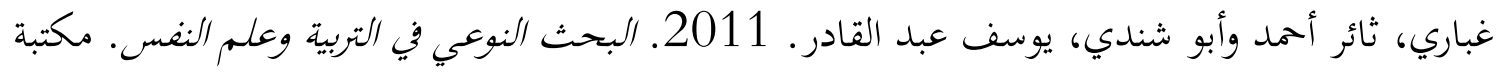

$$
\begin{aligned}
& \text { البحمع العربي للنشر والتوزيع: عمان-الأردن. } \\
& \text { مدكور، علي أحمد. 2010. طرق تدريس اللغة العربية. دار المسيرة للنصر والتوزيع : عمان. }
\end{aligned}
$$

Asrori, Imam. 2013. 1000 Permainan Penyegar Pembelajaran bahasa Arab. Cv Bintang Sejahtera: Malang.

Chakradeo, Neha. N. 2012. Effective Teaching Learning Through Classroom Seminars: A Case Study. Avishkar-Solapur University Research Journal, Vol: 2, 92-97.

Daryanto. 2011. Penelitian Tindakan Kelas Dan Penelitian Tindakan Sekolah Beserta Contoh-Contohnya. Gava Media: Yogyakarta.

Hardiansyah, Heri. 2014. Penggunaan Model Pembelajaran Small Group Discussion Untuk Meningkatkan Hasil Belajar IPS Terpadu di Mts. Jurnal Pendidikan dan Pembelajaran. Volume: 3 No 82014.

Ismail, Achmad Isa. 2014. Improving speaking ability of the eleventh graders of SMAN 12 Surabaya through a small group discussion strategy. Tesis tidak diterbitkan. Malang; Program Studi Pendidikan Bahasa Inggris Universitas Negeri Malang.

Majid, Abdul. 2013. Strategi Pembelajaran. Pt Remaja Rosdakarya: Bandung.

Moeleong, Lexy J. 2000. Metodologi Penelitiam kualitatif. Bandung: Remaja Rosda Karya.

Palappalil, Dhanya Sasidharan. Sushama Jitha \& Ramnath, Sai Nathan. 2016. Effectiveness of modified seminars as a teaching-learning method in pharmacology. International Journal off Applied \& Basic Medical Research. Jul-Sep; 6(3): 195-200.

Safitri, Merry. Gunatama Gede \& Darmayanti. 2014. Keterampilan Membimbing Diskusi Kelompok Kecil Oleh Guru Bahasa Indonesia Di Kelas VII SMP Laboratorium UNDIKSHA. E-Journal Universitas Pendidikan Ganesha Vol: 2 No: I.

Sari, Tri Intan, Mardiati, Yayuk \& Khutobah. 2014. Penerapan Merode Diskusi Dengan Menggunakan Gambar Untuk Meningkatkan Aktifitas Dan Hasil Belajar Siswa Kelas III Dalam Pembelajaran PKN Tema Lingkungan Di SDN Sumberlesung 02 LeduKombo Jember. Jurnal Edukasi UNEJ : I, (2) : 36-39.

Skeff, Kelley M. Campbell, M. \& Jones, H.W. 1986. Evaluation of the Seminar Method to Improve Clinical Teaching. Journal Of General Internal Medicine, Volume I (Sep/Oct).

Sumarni, Harun, Abduh \& Imran. Penerapan Metode Diskusi Untuk Meningkatkan Hasil Belajar Siswa Kelas IV Sekolah Dasar Kecil Toraranga Pada Matapelajaran Pkn Pokok 
Bahasan Sistem Pemerintahan Kabupaten, Kota dan Provinsi. Jurnal Kreatif Tadulako Online Vol 3 No 4 ISSN 2354-614X.

Suwandi, Sarwiji. 2011. Penelitian Tindakan Kelas (Ptk) \& Penulisan Karya Ilmiyah. Yuma Pustaka:Surakarta.

Yulaeha, Wiwin \& Rusdi, Amir. 2016. Pengaruh Penerapan Metode Diskusi Kelompok Kecil Terhadap Hasil Belajar Siswa Kelas V Pada Mata Pelajaran IPS Di Madrasah Ibtidaiyah Nurul Huda Kecamatan Air Sugihan Ogan Komering Ilir. JIP: Jurnal Ilmiah PGMI: Vol:2 No: 2. 